\title{
Measuring Social Intelligence-The MESI Methodology
}

\author{
Miroslav Frankovský ${ }^{1} \&$ Zuzana Birknerová $^{1}$ \\ ${ }^{1}$ Department of Managerial Psychology, Faculty of Management, University of Prešov in Prešov, Slovakia \\ Correspondence: Miroslav Frankovský, Fakulta Manažmentu PU, Konštantínova 16, 08001 Prešov, Slovakia. \\ E-mail: miroslav.frankovsky@unipo.sk
}

$\begin{array}{lc}\text { Received: October 20, } 2013 & \text { Accepted: January 28, } 2014 \quad \text { Online Published: February 26, } 2014 \\ \text { doi:10.5539/ass.v10n6p90 } & \text { URL: http://dx.doi.org/10.5539/ass.v10n6p90 }\end{array}$

The research is supported by project VEGA grant 1/0637/12.

\begin{abstract}
In relation to the problem of conceptualization and operationalization of social intelligence, several issue areas are discussed. This report presents an analysis of the extracted factor structure of the MESI methodology which represents the psychometric approach to studying and measuring social intelligence. The results of the research carried out on the sample of 1130 respondents enabled extraction of the structure of the MESI methodology factors (manipulation, empathy and social irritability). The report also introduces the full version of the MESI methodology.
\end{abstract}

Keywords: social intelligence, manipulation, empathy, social irritability, MESI

\section{Introduction}

Conceptualization and operationalization of social intelligence, i.e. theoretical definition and verification of the procedure and the tool for detection and measurement of social intelligence, are two essential issues without solving which it is impossible to think productively about any category within any area of knowledge and therefore think meaningfully about the category of social intelligence. It is not surprising that the discussions about the theoretical definition of social intelligence and subsequently also about the possibilities of its quantification are in the center of attention of those authors who focus on this problem. The aforementioned discussions, which had developed as part of conceptualization and the subsequent operationalization of social intelligence, concentrate the attention of authors on at least four sets of issues (Frankovský et al., 2012):

1) Distinguishing and specification of the definition of social intelligence in connection to the similar, related areas of knowledge.

2) Ethical dimension of the concept of social intelligence.

3) Definition of the structural elements of the social intelligence construct.

4) Personality and psychometric approach to studying and detecting social intelligence.

\section{Social Intelligence}

The first two areas of issues of studying the concept of social intelligence presented in the introduction of this report are related primarily to conceptualization, or theoretical definition of social intelligence. Discussions about social intelligence (definition, differentiation from other related notions, meaningfulness) are connected to a much more general discussion about the issues of defining intelligence as such. On the basis of the results gained from the answers to questions of how you imagine the concept of intelligence and how to study it, and the opinions of Sternberg and Detterman (1986), Ruisel (2004) pointed out the obvious diffusion in understanding the notion of intelligence also within the professional community of psychologists. Ruisel (2004) sees this as a result of the beliefs that intelligence:

1) is a quality of intellect;

2) is an individual and unique attribute;

3) accurately copies the process of logical operations.

However, the author states that intelligence: 
1) significantly regulates also the actual behavior and therefore $i$ tis inevitable to regard the qualities such as effectiveness and usefulness of what people do or would like to do;

2) represents a diverse entity, a complex of many components;

3 ) is not only a cognitive ability. Intelligent behavior is related also to the conative, affective, personality, or social factors. These factors essentially create the autonomous components of intelligence.

In the context of considering the autonomous components of intelligence, since the 1920s the thoughts were given also to the existence of social intelligence, which was defined by Thorndike (1920) as an ability to understand and manage other people and act wisely in interpersonal relationships. Social intelligence is an actual individual characteristic. Despite this fact, when trying to define it more accurately, certain difficulties emerge (Silvera, Martinussen, \& Dahl, 2001).

Thorndike (1920) in his definition decided to use the two-factor structure for defining social intelligence and within this structure he distinguishes between the cognitive elements (understanding other people) and the behavioral elements (wise behavior in interpersonal relationships) of social intelligence. Marlowe (1986) defines social intelligence similarly. He sees it as an ability to understand others and their social interactions and apply this knowledge in leading and influencing other people for their mutual satisfaction. Considering these concepts it is obvious that social intelligence is a real individual characteristic specified mostly in a positive way in both ethical and pro-social contexts.

The existence of social intelligence is supported also by the opinion of Gardner (1983), according to which it is impossible to consider only a single intelligence but contrarily is necessary to specify the individual types of intelligence. In this sense Orosová and Gajdošová (2009) point out the ability of a person to understand feelings, thinking and behavior of other people as well as their own and based on this understanding to behave accordingly. If the level of these human abilities is low it may cause problems in social relationships. Developing socially intelligent behavior of an individual assumes improvement in self-reflection, reflection of social processes, reflection of the subjective sense and interpretation of behavior, and training social skills.

Although some researches did not confirm the existence of the differences between social and academic intelligence, there are other (Ford \& Tisak, 1983), which detected these differences. Analogical findings could be found also in the analysis of the links between emotional and general intelligence (Ugwu, 2011).

The concept of social intelligence is, content-wise, very closely related to emotional intelligence. The close relationship between social and emotional intelligence was pointed out by Bar-On (2006) who claims that they are labels of two aspects of the same construct and that the majority of the existing definitions of social and emotional intelligence contains one or more of the following abilities:

1) to understand and constructively express emotions,

2) to understand the experiencing of other people and create cooperative interpersonal relationships,

3) to manage and regulate emotions effectively,

4) to cope with the new situations realistically and solve problems of a personal or interpersonal nature, to be optimistic, positively charged and internally motivated to formulate and reach goals.

Two groups of characteristics, which represent the intrapersonal level (knowledge and awareness of own positive and negative qualities and experiencing) as well as the interpersonal level (knowledge and awareness of the qualities and experiencing of other people) meet in the concept presented by this author. To characterize social intelligence from the viewpoint of this concept it is essential to concentrate on both levels. Therefore it is not sufficient to simply know, be aware of, and predict the behavior and experiencing of others but along with this to know and understand our own abilities and skills. Similarly to Bar-On (2006), emotional intelligence is characterized within the research of commercial consultants by, for example, Sarinnapakorn and Sucaromana (2013).

The issue related to the ethical nature of social intelligence is under discussion of a lesser extent. In the common everyday language, "socially intelligent behavior" is more or less automatically evaluated as pro-social, moral, ethical. Kosmitzki, John (1993), and Kaukiainen et al. (1999) presume that social intelligence is charged neutrally and that one of its components is also the use of social techniques for manipulation of others, therefore it is a construct which may be used both in the socially positive and the socially negative sense. Social intelligence is thus placed between the personality traits of pro-social behavior and the area closely related to, for example, the machiavellian intelligence (Ruisel, 2004; Andrew et al., 2008, etc.).

Goleman (2006) states that many psychologists are cynical when it comes to the issue of intelligence within 
interpersonal relationships, and they regard it as an ability to manipulate people to do what you want regardless what they want themselves. The core of manipulation is to affect people as well as social groups. This affecting is based on the manipulator who uses their knowledge about the social rules to develop the desired influence on another person or group of people in a way that these are not aware of the fact that they are being deliberately influenced. He claims that the interest of an individual is not always identical with the interest of the society. This area was characterized in the introduction as the second set of the studied issues connected to the ethical dimension of social intelligence.

The discussion about a mosaic of aspects of the notion of social intelligence content structure (the third set of issues) results in accentuation of either the cognitive dimension of understanding this notion, i.e. the ability to understand other people (Barnes \& Sternberg), or in focusing on behavior, i.e. solving the interpersonal situation (Ford \& Tisak) and stressing the behavioral aspect of the given problem. Characterization of these two aspects of the social intelligence construct structure is, as it was already mentioned, related to Thorndike's (1920) approach to social intelligence.

Stressing the cognitive approach in defining social intelligence is related to how an individual understands and interprets their own behavior as well as the behavior of others and also how in connection to this interpretation they can adjust their behavior effectively. Silvera, Martinussen and Dahl (2001) add that social intelligence consists of these components: perceptiveness of the internal states and moods of other people; general ability to deal with other people; knowledge of the social norms of the social life; ability to orient oneself within social situations; use of social techniques which enable manipulation; social charm and social adaptation.

Kosmitzki and John (1993) proposed similar social intelligence components: Perception of the mental states and moods of other people; general ability to get along with other people; knowledge of the social rules; insight and perception of the complex social situations; use of social techniques to manipulate others; taking over the perspectives of others; social adaptation.

The operationalization of the notion of social intelligence is connected to specification of the psychometric and personality approaches as the two main lines of the studies of social intelligence (Kihlstrom \& Cantor, 2000) which represent the fourth discussed problem of this area of knowledge. The psychometric approach conceptualizes and operationalizes social intelligence as an ability or a set of abilities by means of which people may be compared on a low vs. high dimension and in this case the difference from the studies of academic intelligence lies primarily in the focus on the social sphere. Contrarily, the representatives of the personality approach consider social intelligence on the basis of behaving in various interpersonal situations which is not evaluated strictly on the performance dimension. Considerable attention is paid to the aspect of the subjective evaluation of a situation. The question of the objective of developing methodology for measuring social intelligence oriented personality-wise or psychometrically resonated also in our efforts to propose and verify a measuring tool for this construct (Frankovský, Štefko, \& Baumgartner, 2006).

\section{Research Method}

The presented research was carried out with the help of 1130 respondents. The total number contained $21.9 \%$ of men and $78.1 \%$ of women. The respondents were structurally divided into $2.3 \%$ of top managers, $3.6 \%$ of middle managers, $5.5 \%$ of line managers, $23.4 \%$ of efficient workers and $65.2 \%$ of management students. Their average age was 25.5 years (with the standard deviation of 7.301 years). The minimum age of the respondents in the research sample was 18, the maximum age was 57 years. The respondents' data were gained by the questionnaire method and were subsequently processed and analyzed by the mathematical and statistical methods. The data about the basic socio-demographic characteristics of the respondents and their social intelligence degree were gained by means of two questionnaires-the newly emerged MESI and the already existing TSIS (Silvera, Martinussen, \& Dahl, 2001).

\subsection{TSIS Methodology}

TSIS-Tromso Social Intelligence Scale (Silvera, Martinussen, \& Dahl, 2001) consists of 21 self-evaluation items to which the respondents respond on a 7-point scale of the agreement degree (1-describes me very poorly, 7-describes me very well). The questionnaire is divided into 3 subscales which enable specification of 3 factors:

1) SP-social information processing (e.g. I can easily understand social situations.)

2) SS-social skills (e.g. I am successful in establishing new relationships.)

3) SA-social awareness (e.g. I am often surprised how other people react to my actions.)

The internal validity of these factors is given as follows: SP-0.79, SS-0.85 and SA-0.72 (Silvera, Martinussen, 
Dahl, 2001). The factors of the scale statistically significantly intercorrelate.

\subsection{MESI Methodology}

The presented MESI methodology aimed to detect social intelligence on the basis of the psychometric approach is a developing continuation of the EMESI methodology (Frankovský \& Birknerová, 2013), which was inspired by the PESI methodology created by the authors Kaukiainen, Björkqvist, Osterman, Lagerspetz, and Forsblom (1995). This methodology was developed for the peers or their teachers and was used to detect the degree of perceiving social intelligence as a performance characteristic. It consists of 10 items and its internal consistency (Cronbach's alpha) was 0.90. The MESI methodology contains 21 items evaluated on a 5-point scale (0-never, 4-very often). Formulation and selection of the individual items were based on the experience gained from the former EMESI methodology, interviews with the respondents, the Cronbach's alpha results and a discriminant item analysis (Frankovský \& Birknerová, 2013).

\subsubsection{The Complete MESI Methodology}

Please, read each statement carefully and state to what extent it corresponds with your way of reacting. The purpose of this questionnaire is to study how people act in social situations. Respond by marking the one alternative which most closely expresses your experience. Mark your response by crossing one of the numbers on the scale from 0 to 4 in accordance with the following:

Table 1.

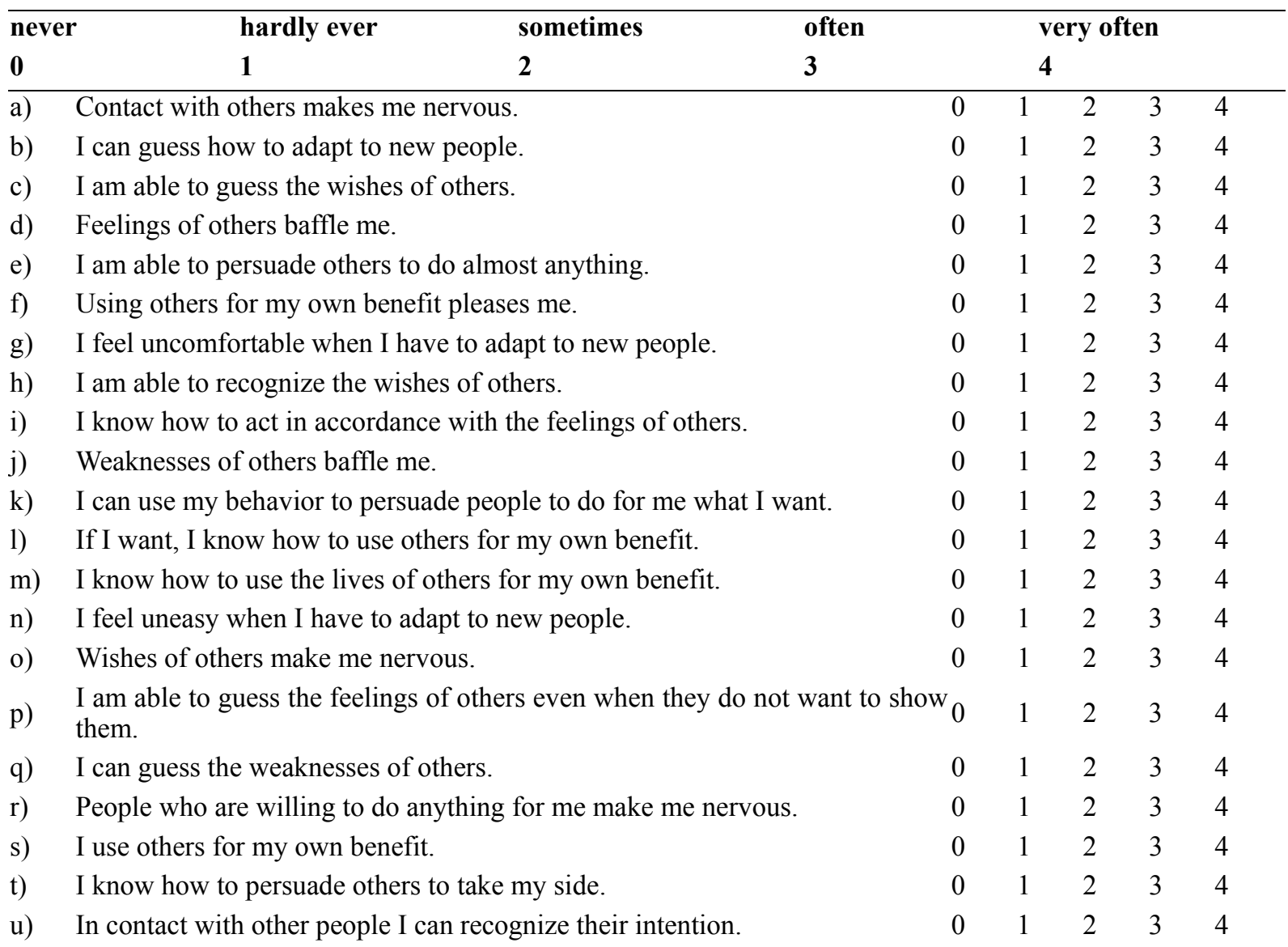

\section{Results}

The main aim of this research was to verify the methodology for measuring social intelligence on the basis of the psychometric approach. The factor analysis (Principal Component Analysis with Varimax rotation) extracted 3 social intelligence factors (Figure 1, Table 2) which were labeled:

1) Manipulation: People who have higher scores in this factor are able to persuade others to do almost anything. They can use others for their own benefit and persuade them to take their side. They use the lives of others for 
their own advantage.

2) Empathy: Individuals with higher scores in this factor are able to recognize the intentions, feelings, and weaknesses of other people. They can adapt to new people, guess their wishes as well as fulfill them. Empathy is characterized in the context of definitions as stated by Chen (2008).

3) Social irritability: Persons characterized by higher scores in this factor are nervous in contact with other people. Feelings of others baffle them, adapting to other people is a problem for them. Weaknesses and wishes of others confuse them. They become nervous around people who are willing to do anything for them.

Scree Plot

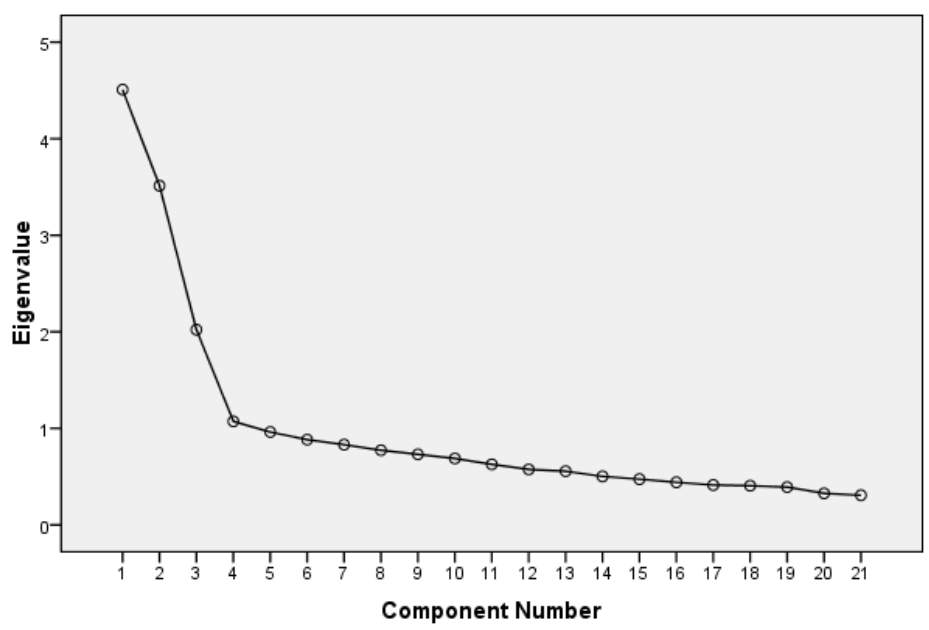

Figure 1. Illustration of the factors by means of a Scree Plot

Table 2. Factor structure of the MESI methodology

\begin{tabular}{|c|c|c|c|c|}
\hline No. & Items & F1 & F2 & F3 \\
\hline 1. & Contact with others makes me nervous. & & & .623 \\
\hline 2. & I can guess how to adapt to new people. & & .627 & \\
\hline 3. & I am able to guess the wishes of others. & & .452 & \\
\hline 4. & Feelings of others baffle me. & & & .599 \\
\hline 5. & I am able to persuade others to do almost anything. & .640 & & \\
\hline 6. & Using others for my own benefit pleases me. & .706 & & \\
\hline 7. & I feel uncomfortable when I have to adapt to new people. & & & .667 \\
\hline 8. & I am able to recognize the wishes of others. & & .745 & \\
\hline 9. & I know how to act in accordance with the feelings of others. & & .608 & \\
\hline 10. & Weaknesses of others baffle me. & & & .457 \\
\hline 11. & I can use my behavior to persuade people to do for me what I want. & .736 & & \\
\hline 12. & If I want, I know how to use others for my own benefit. & .814 & & \\
\hline 13. & I know how to use the lives of others for my own benefit. & .702 & & \\
\hline 14. & I feel uneasy when I have to adapt to new people. & & & .776 \\
\hline 15. & Wishes of others make me nervous. & & & .636 \\
\hline 16. & I am able to guess the feelings of others even when they do not want to show them. & & .730 & \\
\hline 17. & I can guess the weaknesses of others. & & 653 & \\
\hline 18. & People who are willing to do anything for me make me nervous. & & & .421 \\
\hline 19. & I use others for my own benefit. & .763 & & \\
\hline 20. & I know how to persuade others to take my side. & .670 & & \\
\hline \multirow[t]{3}{*}{21.} & In contact with other people I can recognize their intention. & & .689 & \\
\hline & Eigenvalue & 4.508 & 3.512 & 2.021 \\
\hline & $\%$ total variance & 21.468 & 16.725 & 9.626 \\
\hline
\end{tabular}


The extracted factors explain $47.8 \%$ of variance. This percentage of the variance explained by the extracted factors is acceptable; the factors could be specified content-wise.

The internal consistency of the individual factors as an indicator of reliability of the individual methodology factors was detected by calculating the Cronbach's alpha coefficient (Table 3).

Table 3. Cronbach's alpha values for the defined factors of the MESI methodology

\begin{tabular}{llll}
\hline & F1 manipulation & F2 empathy & F3 social irritability \\
\hline Cronbach's alpha & .854 & .783 & .716 \\
\hline
\end{tabular}

The detected values of the Cronbach's alpha coefficient are a proof that the internal consistency of the items saturating the specified factors is in the zone of acceptability.

The proposed structure of the defined factors of the MESI methodology is supported also by the values of the calculated intercorrelational coefficients between the individual factors (Table 4). The extracted factors of MESI intercorrelate or, in other words, they are at the border of a statistically significant correlation. This is documented by the fact that these factors which represent the indicators of social intelligence mutually intercorrelate. Statistically significant values of these correlations are, however, not sufficiently high which means that they describe related but still different areas of social intelligence.

The detected positive correlation between empathy and manipulation highlights the fact that manipulation of other people is connected to the ability to penetrate into their thinking, feelings, experiencing, to understand them and use them for own benefit (which is sometimes beneficial to these people as well). Nevertheless, empathy negatively correlates with social irritability. It means that only those people can behave empathically whose presence does not disturb or irritate other people and is not unpleasant to them. Statistically significant is also the positive correlation between manipulation and social irritability. The presented findings may be interpreted as documenting the fact that manipulation with people is related to more frequent feelings of social irritability (e.g. People who are willing to do anything for me make me nervous.).

Table 4. Values of the intercorrelation coefficients between the MESI factors

\begin{tabular}{llll}
\hline & F1 manipulation & F2 empathy & F3 social irritability \\
\hline F1 manipulation & - & $.241^{* *}$ & $.134^{* *}$ \\
F2 empathy & & - & $-.159^{* *}$ \\
F3 social irritability & & & - \\
\hline
\end{tabular}

*statistical significance on 0.05 level of significance

**statistical significance on 0.01 level of significance

Validity of the presented MESI methodology was detected in relation to Tromso Social Intelligence Scale-TSIS (Silvera, Martinussen, \& Dahl, 2001). Comparison of the results gained by means of this questionnaire and MESI brought about some important pieces of knowledge used for confirmation of the content validity of the internal structure of the emerging methodology (Table 5).

Table 5. Correlation coefficients between the factors of MESI and TSIS

\begin{tabular}{llll}
\hline Strategies & SP-social information processing & SS-social skills & SA-social awareness \\
\hline F1 manipulation & $.189^{* *}$ & $.221^{* *}$ & $-.088^{* *}$ \\
F2 empathy & $.617^{* *}$ & $.355^{* *}$ & $.192^{* *}$ \\
F3 social irritability & $-.257^{* *}$ & $-.513^{* *}$ & $-.369^{* *}$ \\
\hline
\end{tabular}

The expected high statistically significant positive correlation between the MESI factors of empathy and manipulation and the TSIS factor of social information processing was detected. The quality of social information processing is an essential component of the level of empathy as defined in the content specification 
of the extracted factors which is the degree in which it is possible to recognize intentions, feelings and weaknesses of others. People are able to adapt to others, guess their wishes as well as fulfill them. The level of social information processing is also important for manipulation.

The MESI factor of social irritability correlates negatively with all three TSIS factors. This means that implementation of social intelligence and its individual components are connected significantly to the control of one's own emotions. Contrarily, it is impossible to expect a high level of social intelligence and effective solving of social situations from a person who cannot control these emotions and whose emotions strongly influence his or her cognitive and behavioral reactions in social situations.

Interestingly, the MESI factor of manipulation correlates positively with two TSIS factors-social skills and social information processing. These correlations confirm the initial assumption that social intelligence is neutrally charged which was discussed in the introduction of this article connected to the understanding of social intelligence within the context of discussions about its possible pro-social or anti-social character (Kosmitzki \& John, 1993; Kaukiainen et al., 1999). The factor of manipulation simultaneously correlates negatively with the factor of social awareness which is clearly pro-socially charged.

\section{Conclusion}

Social intelligence is a significant factor of prediction and interpretation of human behavior in various social contexts of social practice. It is assumed that the presented concept and methodology for detection of social intelligence as one of the performance characteristics of a person is productive. So far the acquired verification data about the concept and the methodology serve as an evidence of the meaningfulness of this process and are in favor of application of the performative approach to measuring social intelligence which is, from the viewpoint of practical needs and use, very desirable in practice. Simultaneously, the presented findings confirm the idea about the neutral charge in the pro-social sense and its effects on behavior. The MESI methodology, in comparison to TSIS, represents a broader concept of the view of social intelligence which includes cognitive, emotional and social components.

We are fully aware of the limitations and shortcomings of our findings and the necessity to verify the presented concept and methodology in much broader contexts, particularly with regard to the cultural one.

\section{References}

Andrew et al. (2008). The relationship between empathy and Machiavellianism: An alternative to empathizing-systemizing theory. Personality and Individual Differences, 44, 1203-1211. http://dx.doi.org/10.1016/j.paid.2007.11.014

Barnes, M. L., \& Sternberg, R. J. (1989). Social intelligence and decoding of nonverbal cues. Intelligence, 13, 263-287. http://dx.doi.org/10.1016/0160-2896(89)90022-6

Bar-On, R. (2006). The Bar-On Model of Emotional-Social Intelligence (ESI). Psicothema, 18, 13-25.

Chen, L. (2008). The Effect of Empathy on College English Speaking. Asian Social Science, 4(8), 142-146.

Ford, M. E., \& Tisak, M. S. (1983). A further search for social intelligence. Journal of Education Psychology, 75, 196-206. http://dx.doi.org/10.1037/0022-0663.75.2.196

Frankovský, M., \& Birknerová, Z. (2013). Differences in social and machiavellian intelligence between the management students from Czech and Slovak republic. CBU International Conference Proceedings 2013, 135-143. Prague: Central Bohemia University. http://dx.doi.org/10.12955/cbup.2013.26

Frankovský, M., Lajčin, D., \& Sláviková, G. (2012). Social intelligence as a predictor of managers' behaviour in demanding situations of managerial work. Management 2012: Research management and business in the light of practical needs, 476-486. Prešov: Bookman.

Frankovský, M., Štefko, R., \& Baumgartner, F. (2006). Behavioral-situational approach to examining social intelligence. Studia Psychologica, 48(3), 251-258.

Gardner, H. (1983). Multiple Intelligences: The Theory of Multiple Intelligences. New York: Basic Books.

Goleman, D. (2006). Emotional Intelligence. New York: Bantam Books.

Kaukiainen, A., Bjorkqvist, K., Osterman, K., Lagerspetz, K., \& Forsblom, S. (1995). Peer-Estimated Social Intelligence (PESI). Turku, Finland: Department of Psychology, University of Turku.

Kaukiainen, A., Bjőrkvist, K., Lagerspetz, K., Österman, K., Salmivalli, C., Rothberg, S., \& Ahlborn, A. (1999). The Relationships between Social Intelligence, Empathy, and Three Types of Aggression. Aggressive 
Behavior, 25, 81-89. http://dx.doi.org/10.1002/(SICI)1098-2337(1999)25:2<81::AID-AB1>3.0.CO;2-M

Kihlstrom, J. F., \& Cantor, N. (2000). Social Intelligence. In R. J. Sternberg (Ed.), Handbook of intelligence (2nd ed., pp. 359-379). Cambridge, U.K.: Cambridge University Press. http://dx.doi.org/10.1017/CBO9780511807947.017

Kosmitzki, C., \& John, O. P. (1993). The implicit use of explicit conceptions of social intelligence. Personality and Individual Differences, 15, 11-23. http://dx.doi.org/10.1016/0191-8869(93)90037-4

Marlowe, H. A. (1986). Social Intelligence: Evidence for Multidimensionality and Construct Independence. Journal of Educational Psychology, 78, 52-58. http://dx.doi.org/10.1037/0022-0663.78.1.52

Orosová, O., \& Gajdošová, B. (2009). The Association of Social Intelligence Factors, Normative Expectations, and Perceived Accessibility with Legal Drug. Adiktologie, 4, 204-211.

Ruisel, I. (2004). Intelligence: Researches of Psychologists from the Slovak Academy of Sciences. Psychology Science, 46.

Sarinnapakorn, F., \& Sucaromana, U. (2013). Emotional Intelligence among Business Consultants: A Comparative Study. Asian Social Science, 9(3), 1-6. http://dx.doi.org/10.5539/ass.v9n3p1

Silvera, D. H., Martinussen, M., \& Dahl, T. I. (2001). The Tromso Social Intelligence Scale, a self-report measure of social intelligence. Scandinavian Journal of Psychology, 42, 313-319. http://dx.doi.org/10.1111/1467-9450.00242

Sternberg, R. J., \& Detterman, D. K. (1986). What is intelligence? Contemporary viewpoint on its nature and definition. Hillsdale: Ablex.

Thorndike, E. L. (1920). Intelligence and its use. Harper's Magazine, 140, 227-235.

Ugwu, L. I. (2011). Emotional and General Intelligence: Characteristics, Meeting Points and Missing Links. Asian Social Science, 7(7), 137-140. http://dx.doi.org/10.5539/ass.v7n7p137

\section{Copyrights}

Copyright for this article is retained by the author(s), with first publication rights granted to the journal.

This is an open-access article distributed under the terms and conditions of the Creative Commons Attribution license (http://creativecommons.org/licenses/by/3.0/). 